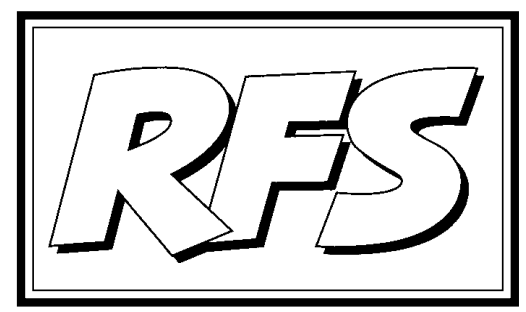

Revista de Fomento Social, 58 (2003), 365-376

\title{
La enseñanza de la religión en la nueva legislación
}

J osé M. MARGENAT PERALTA S.J.*

( Palabras clave: Religión, Objetivos educativos, Pacto político.

Key words: Religion, Educational objectives, Policital pact)

La reciente LEY ORGÁNICA DE CALIDAD DE LA EDUCACIÓN (LOCE) ha abordado el problema de la enseñanza de la religión en la escuela (ERE, entendida en esta nota siempre en sentido confesional) con una regulación aparentemente coherente con el texto constitucional y el bloque de la constitucionalidad. En esta nota me intereso por la ERE sólo desde esa perspectiva constitucional; creo que es la única que puede regular legítima y prácticamente el derecho a la educación de los ciudadanos. Excluyo, pues, en este escrito cualquier referencia al derecho concordatario y, por tanto, a los Acuerdos entre la Santa Sede y el Estado español de 1979¹.

* Profesor de Pensamiento Social Cristiano en ETEA, Universidad de Córdoba. Entre 1987 y 1989 el autor fue asesor técnico del Ministerio de Educación (Ministerio Maravall Herrero) y colaborador de la Comisión Episcopal de Enseñanza (presidencia del arzobispo Delicado Baeza).

1 Una versión anticipada de este texto apareció en la revista de profesores Religión y Escuela, 
Me refiero en la nota a dos dimensiones: interna (coherencia argumentativo-educativa de la LOCE) y externa (oportunidad política de esta ley). La tesis, que expongo desde el inicio, es que la propuesta de la $\mathrm{LOCE}^{2}$ es una solución acertada y progresista, aunque problemática, desde el punto de vista legal, e inestable, desde el punto de vista del debate político ${ }^{3}$.

La LOCE ha regulado, por primera vez de forma explícita en una Ley Orgánica ${ }^{4}$, la enseñanza de la religión en su modalidad confesional y en la no confesional. En su disposición adicional segunda la LOCE establece:

«Del área o asignatura de Sociedad, Cultura y Religión.

1. El área o asignatura de Sociedad, Cultura y Religión comprenderá dos opciones de desarrollo: una de carácter confesional, acorde con la confesión por la que opten los padres 0 , en su caso, los alumnos, entre aquellas respecto de cuya enseñanza el Estado tenga suscritos Acuerdos; otra, de carácter no confesional. Ambas opciones serán de oferta obligatoria para los centros, debiendo elegir los alumnos una de ellas.

2. La enseñanza confesional de la Religión se ajustará a lo establecido en el Acuerdo sobre enseñanza y asuntos culturales suscrito entre la Santa Sede y el Estado Español $y$, en su caso, a lo dispuesto en aquellos otros suscritos, o que pudieran suscribirse, con otras confesiones religiosas.

3. El Gobierno fijará las enseñanzas comunes correspondientes a la opción no confesional. La determinación del currículo de la opción confesional será competen-

no 166, enero de 2003, pp. 33-35. En el presente texto modifico y amplío aquella reflexión, introduciendo todo lo referente a las más recientes disposiciones del Ministerio de Educación sobre el currículo de Sociedad, Cultura y Religión. La reciente aprobación de los Decretos que regulan las enseñanzas comunes desde los 6 hasta los 18 años han aclarado algunas cuestiones que en enero eran problemáticas, y así lo hago constar en el texto cuando procede.

2 BOE no 307, 24-12-2002, pp. 44188-45220.

3 Aquel intento de decreto nonnato, llamado borrador Rajoy, que apareció en la prensa a primeros de noviembre de 1999, presentaba grandes dificultades, cfr. MARGENAT, J. M. (2000) Religión y Escuela, ( $n$ - 136, enero). En otras dos ocasiones, recientemente, me he referido a este problema de la ERE y a ellas me remito para no repetir los mismos argumentos: MARGENAT, J. M. (1996), Revista de Fomento Social y Margenat, J. M. (2000), Iglesia Viva. Revista de Pensamiento Cristiano. En la segunda de las contribuciones reproducía parte de la primera reelaborada y proponía algunos argumentos para debate.

4 La LOGSE (1990) se ocupó de la ERE sólo en su sentido confesional y sólo para hacer una regulación que entonces llamé tautológica, pues se limitaba a remitir a los Acuerdos concordatarios de enero de 1979, y no entraba en el fondo de la cuestión, ignorando, sin negarlas, las perspectivas abiertas por la Constitución, la Ley Orgánica del Derecho a la Educación y la Ley Orgánica de Libertad religiosa. 
cia de las correspondientes autoridades religiosas. Las decisiones sobre utilización de libros de texto (...).

4. Los profesores (...)».

Para desarrollar la LOCE, el Gobierno acaba de aprobar los RR.DD. de 27 de junio, 830/2003, 831/2003 y 832/2003 por los que se establecen respectivamente las enseñanzas comunes de la Educación Primaria, de la Educación Secundaria Obligatoria y del Bachillerato ${ }^{5}$. Con ellos se da un paso más, ciertamente importante, para la implantación del nuevo modelo de enseñanza religiosa escolar. En la LOCE se establece que el área o asignatura, según niveles, SCR (Sociedad, Cultura y Religión, en este escrito siempre en sentido englobante de las dos modalidades: confesional y no confesional, o referida, por exclusión, sólo a la modalidad no confesional, según el contexto) es obligatoria para todos los alumnos ${ }^{6}$, con dos opciones de desarrollo: confesional y no confesional.

\section{Una solución problemática para los principios de integralidad y de pluralidad}

Dos principios educativos constitucionales, complementarios y no opuestos entre sí, concurren a formar la cultura constitucional sobre la enseñanza escolar de la religión y deben conformar la voluntad del legislador. Los llamaré, de forma breve, principio de integralidad y principio de pluralidad. Desde el punto de vista interno y legal, la solución de una asignatura SCR

5 BOE nn. 157 (2-7-2003), pp. 25446 y 25464-25466 (Primaria), 158 (3-7-2003), 25687 y $25716-$ 25718, y 159 (4-7-2003) 26042 y 26060-26061. En los tres casos una disposición adicional primera reproduce en lo esencial la citada disposición adicional de la LOCE por lo que se hace explícita la opción de Sociedad, Cultura y Religión. Los párrafos 1 y 2 reproducen los correspondientes 1 y 2 de la adicional 2 a de la LOCE. El párrafo 3 también hace lo propio, salvo que donde la LOCE dice «EI Gobierno fijará las enseñanzas comunes correspondientes a la opción no confesional», el RD 830/2003 y los restantes citados dicen que «Las enseñanzas comunes de la opción no confesional están incluidas en el anexo I [de dicho Decreto, se entiende]». Por último, el párrafo 4 se refiere a que el procedimiento de elección de la opción de desarrollo, confesional o no confesional, se realizará de acuerdo con el RD 2438/1994. El RD sobre educación infantil ha sido igualmente aprobado, pero lo dejo aparte en esta nota.

6 En realidad esta proposición es tan antigua como la propuesta que en febrero de 1989 aprobó la Comisión Episcopal de Enseñanza que, con importantes modificaciones posteriores introducidas por presión de los sectores eclesiásticos más conservadores, fue presentada al Ministerio de Educación en abril de ese mismo año; cfr. MARGEnAT, J. M. (1989), «Religión para todos», en La Vanguardia, Barcelona, 5-2-1989. 
obligatoria, que establece la LOCE, parece coherente con el art. 27.2 de la Constitución (educación integral, art. 2.2.a, de LOCE) y con el art. 27.3 de la Constitución (educación plural, art. 2.2.b, de LOCE), en cuanto la misma arbitra un sistema que posibilita la integralidad y la pluralidad, a las que deben contribuir estas enseñanzas. La cuestión central, que hemos de plantearnos en esta nota, es si la obligatoriedad de SCR forma parte de la regulación necesaria para la integralidad y para la pluralidad y su porqué. La LOCE (disposición adicional 2a, párrafo 1, parece afirmarlo taxativamente: “El área o asignatura de Sociedad, Cultura y Religión comprenderá dos opciones de desarrollo: una de carácter confesional, acorde con las confesión por la que opten los padres 0 , en su caso, los alumnos, (...); otra, de carácter no confesional. Ambas opciones serán de oferta obligatoria por los Centros, debiendo elegir los alumnos una de ellas" ${ }^{\prime 7}$ ). Me refiero, pues, en primer lugar a este aspecto.

Es indiscutible la obligatoriedad que tienen los centros de titularidad pública de ofrecer la ERE, como ya reconocía la LOGSE (1990, Ministerio Solana Madariaga) en su disposición adicional segunda ( ¿y los centros de iniciativa social, concertados y financiados con fondos públicos, pero con un proyecto educativo definido a partir de su carácter propio?). Es discutible, sin embargo, la obligatoriedad de elección por parte de los alumnos. Decir que es discutible no quiere decir que sea rechazable, sino que hay discutirla, es decir aclarar desde qué supuestos se realiza esa elección obligatoria entre una y otra opción de desarrollo. Veámoslos; la obligatoriedad puede derivar de dos supuestos: la contribución a la formación integral del alumno dentro del cuadro de las finalidades educativas de la escuela o el apoyo positivo al ejercicio efectivo del derecho a la religión y a la educación religiosa, consiguiendo un cierto equilibrio organizativo pedagógico para que el ejercicio de ese derecho sea moderadamente apoyado por los poderes públicos de acuerdo con la lógica de "cooperación positiva" de la Constitución (art. 16.1) y no sea, de hecho, prácticamente inviable. Dicho de otra manera: desde el principio de integralidad o desde la cooperación positiva al principio de pluralidad. Me parece sumamente importante saber de cuál de los dos supuestos hemos de partir; esto no lo hacen explícito la LOCE ni los RR.DD. de desarrollo.

La integralidad de la educación de unos alumnos no puede implicar la obligatoriedad de una enseñanza para los otros alumnos. Si para la educación

7 La LOGSE decía: oferta obligatoria para los centros y optativa para los alumnos. 
integral de unos alumnos es muy importante una enseñanza escolar de la religión, de ello no se puede derivar una situación de obligación para todos, y por tanto para los demás (lo que el exministro Suárez Pertierra formuló provocativa y punzantemente: ipueden obligarme a jugar al fútbol porque otros quieran ir a misa?). Pero si se logra mostrar educativamente que para todos es importante, y aún necesaria, una enseñanza escolar de la religión, en ese caso podríamos hablar de una integralidad que exige la obligatoriedad. Urge que el Gobierno, que ha presentado la LOCE y los decretos que la desarrollan, pero sobre todo el Parlamento cuando proceda realizar ese debate, defina esta cuestión: la asignatura o área de Sociedad, Cultura y Religión, ¿es necesaria para conseguir los objetivos educativos de la LODE y de la LOGSE que desarrollan el mandato constitucional (art. 27.2, "integralidad"), o es sólo necesaria para que algunos alumnos consigan desarrollar el mandato constitucional de una educación conforme a los propios valores y creencias (art. 27.3, "pluralidad" desde la cooperación positiva)?

Si la ERE contribuyese, dentro del área o asignatura de SCR y en el cuadro de las finalidades de la escuela (definidas en los arts. 2.a, 2.b, 2.f y, por extensión, a los otros fines: 2.c., 2.d, 2.e y 2.g; 4.a, 4.b; 6.a, 6.c de la LODE y arts. 1.1 y 2.3.a de la LOGSE), a la formación integral de los alumnos desde el patrimonio cultural y desde la ciudadanía, de ahí se derivaría la obligatoriedad de la elección entre quienes quisiesen servirse de esa área o asignatura y quienes prefiriesen hacerlo de otra 'opción de desarrollo' aconfesional para alcanzar los mismos objetivos comunes. Pero en ese caso lo que le correspondería a la ERE es demostrar dos cosas: que por medio suyo se alcanzan los objetivos comunes y que sólo gracias a SCR, sea la ERE, sea una modalidad similar no confesional ('opción de desarrollo' según el término de la LOCE), puede alcanzarseel cumplimiento de to dos los objetivos necesarios para una educación integral.

Como consecuencia de lo anterior, desde esa opción se derivaría un tipo de ERE claramente curricular, estructurada y formulada según los principios y las opciones del diseño curricular común de los alumnos, y según sus opciones de fondo y de método (cfr. LOGSE art. 4.1) ${ }^{8}$. Esta implicación tiene

8 No basta decir, aunque ya suponga un gran avance nunca hasta ahora expresado en un documento oficial estatal, que «las enseñanzas comunes ... han de proponer ... una educación que contribuya al desarrollo integral de todas las capacidades, ... así como los valores que deberán servir de referencia para la formación integral de los alumnos»y que, dentro de ellas, «as enseñanzas de Sociedad, Cultura y Religión, correspondientes a las opciones 
una importancia muy grande, pues no cabrá cualquier ERE, sino sólo aquella que, ya prevista en el documento Orientaciones por el Episcopado Español en junio de 1979, se desarrolle de acuerdo con un claro carácter escolar. Habrá, pues, que excluir toda forma de catequesis, formación doctrinal o meramente moral y lo que generalmente se denomina acción evangelizadora o pastoral. Es cierto que eso no impide considerar a la ERE, como a la educación en general en un proyecto de pastoral o acción evangelizadora de conjunto, pero es claro que esa es otra cuestión. La ERE integrada en el currículo básico tiene que tener un carácter plenamente escolar, formativo, cultural y crítico, y debe desarrollarse dentro de las finalidades de la escuela. Esa ERE, "acorde con la confesión por la que opten los padres o, en su caso los alumnos" (LOCE, disp. adic. 2ạ 1), en el caso de la ERE católica, responderá de su carácter confesional por la razón de la elección de los padres, por la garantía del profesorado encargado (tema muy complejo, y no menos importante, al que habría que dedicar otro comentario complementario) y por la confesionalidad de la orientación educativa, pero no dejará de ser escolar y plenamente curricular. De esta claridad conceptual derivan consecuencias inequívocas para la adecuada comprensión de la misión del profesorado, incluido su sistema de selección, nombramiento y eventual cese.

Pero, ciertamente, cabría otra forma de argumentar. Para el ejercicio positivo del derecho a practicar la propia religión y ser formado en ella

confesional y no confesional, se desarrollarán con estricto respeto a la Constitución española. Los objetivos y contenidos generales se establecen en este real decreto, sin perjuicio de la competencia correspondiente para la determinación del currículo de la opción confesional» (los subrayados son, evidentemente, míos). Tres afirmaciones pretendo retener, que conviene hacer más explícitas: (1) las enseñanzas del área o asignatura SCR surgen dentro de las competencias constitucionales de la autoridad estatal para definir el currículo básico, y no de un principio particular, se incluyen en el currículo por iniciativa del legislador y no para satisfacer un derecho particular de unos ciudadanos, punto al que me referí en mi escrito «Razón de la Constitución, sinrazón del Nuncio», en El País, 28-2-1990, y del que depende la interpretación fundamental que hagamos de este aspecto esencial; (2) los objetivos y contenidos de SCR son comunes para todos y en un primer nivel de concreción curricular los fija la autoridad educativa competente, esto es, la del Estado, dejando para un segundo o posteriores niveles, que sea la propia modulación de una u otra opción de desarrollo la que exija que intervengan unas u otras instancias, por ejemplo las distintas confesiones religiosas establecidas con acuerdo para las enseñanzas confesionales; (3) la enseñanza de SCR se realizará dentro de estricto respeto a la Constitución; esta afirmación tiene un alcance sin precedentes, que nunca se había hecho, con un valor insospechado tanto para la ERE confesional católica, con más años de práctica de convivencia constitucional, como para la ERE de otras confesiones distintas de la católica, cristianas y otras, con mucho menos tiempo de implantación escolar en el sistema educativo democrático. 
(Constitución, art 16.1; Ley Orgánica de Libertad Religiosa, 7/80, de 5-7-1980, arts. 1.1, 2.1.a, 2.1.c, 2.2 y 2.3, y disposiciones antes citadas de la LODE y de la LOGSE), los poderes públicos han de colaborar positivamente con las confesiones que materializan este derecho y han de apoyar el ejercicio del mismo. El Estado español no es un Estado constitucionalmente laico (y menos laicista), sino un Estado aconfesional. El Estado aconfesional no es neutral en relación con el hecho religioso, sino que viene informado por el principio de 'cooperación positiva' con el hecho religioso, como sostienen tanto la Constitución como la Ley de libertad religiosa: “Los poderes públicos tendrán en cuenta las creencias religiosas de la sociedad española y mantendrán las consiguientes relaciones de cooperación..." (Constitución, art. 16.3), "Para la aplicación real y efectiva de estos derechos, los poderes públicos adoptarán las medidas necesarias para facilitar (...) la formación religiosa en centros docentes públicos" (Ley 7/80 de Libertad religiosa, art. 2.3). Esta forma de argumentar no partiría tanto de las finalidades de la escuela (lo que he llamado "curricularidad objetiva") cuanto de la formación de los alumnos desde su propia creencia ("curricularidad subjetiva"). Consecuentemente con esta norma constitucional el Estado podría (y quizá sería mejor decir que debiera) promover y proteger el derecho de los ciudadanos particulares a la educación religiosa que ellos demanden y, realizada la demanda, ejercer cierta discriminación positiva en su favor. El problema es que no está claro el límite de dicha discriminación positiva, pues enfrente tiene a otros ciudadanos a quienes también tiene que proteger y a quienes no puede someter a una situación de obligación para garantizar el derecho de los primeros. Algún grado de apoyo mayor cabe para los que ejercen el derecho a elegir la formación religiosa conforme a sus creencias, pero no cualquier forma deapoyo. La exigencia de una obligatoriedad para todos sólo es aceptable en la lógica de la curricularidad objetiva desde el cuadro de las finalidades de la escuela, mientras que en la lógica de la curricularidad subjetiva, desde el ejercicio del pluralismo y el principio de 'cooperación positiva', sólo cabrán medidas de apoyo efectivo, sin llegar nunca a una obligatoriedad impuesta a todos, que se percibiese y se hubiese de argumentar como condición del ejercicio del derecho a la enseñanza religiosa de una parte de los alumnos, a costa de la imposición de una obligación similar a los otros (a los que no quieren y piden esa enseñanza), pero con fundamentos de naturaleza y alcance de menor entidad.

Debo dejar apuntado otro aspecto muy problemático: la configuración de la educación cívica. Este punto exigiría un desarrollo más amplio, pero algo 
se puede indicar a propósito. La ética pública de mínimos, la ética cívica, la educación para la ciudadanía y el conocimiento y valoración de la Constitución son materias pendientes de nuestro ordenamiento educativo, tan graves o más que el que venimos abordando. No se pueden ni deben mezclar ambos temas. Por tanto hubiese sido radicalmente rechazable que se pretendiese contraponer una educación moral y cívica, o una versión de SCR que incluyese estos aspectos, desde la opción de desarrollo aconfesional ${ }^{9}$. Esta educación cívica a que me refiero debe ser común y obligatoria para todos los alumnos de nuestro sistema educativo. Este carácter común y obligatorio no debe impedir que haya una educación en diferentes éticas de máximos, con vocación de éticas públicas y con significación religiosa, como reconoce el art. 27.3 de la Constitución. Pero de ninguna manera, como hacía el borrador Rajoy (noviembre de 1999), debe plantearse una como alternativa de la otra ${ }^{10}$.

Para terminar, queda la cuestión de si en todos los tramos educativos debería ser obligatoria la elección entre dos opciones de desarrollo, o debe haber niveles educativos con esa educación común para todos y niveles con doble itinerario u opción de desarrollo: aconfesional y confesionales. De momento parece que las recientes disposiciones se inclinan por la primera posibilidad apuntada, pero no habría que descartar el estudio de la segunda, por ejemplo en primaria o en bachillerato.

9 No obstante, esa fue la opción, Religión o Ética, que tras unas órdenes ministeriales provisionales de 1979, reiteradas en los Decretos de Otero Novas de 1980, ha estado vigente en España hasta la LOGSE (1990) y el final de su implantación. Con mayor o menor estabilidad y fortuna, en el sistema educativo español, durante unos dieciocho años, la alternativa a la Religión ha sido la Ética. Los RR.DD. de 27 de junio de 2003 cortan con toda posible interpretación en ese sentido.

10 La LOCE y los RR.DD. citados de julio de 2003 han regulado el aprendizaje y la enseñanza de la Ética en 40 de ESO, cfr. BOE no 158 (3-7-2003), pp. 25726-25727, y queda claro que la Ética es común para todos los alumnos y no se confunde con la ERE ni con SCR ( «Así pues, la Ética constituye una materia propia, autónoma, de carácter filosófico ... En ningún caso y bajo ningún concepto, se puede considerar que la enseñanza de la Ética es una alternativa a la religión o religiones confesionales. LaÉtica debe ser patrimonio común de todos los alumnos y debe contribuir a formar ciudadanos ... »). En la legislación del Estado español es la primera vez que aparece esta formulación de forma clara y terminante. Éstees uno de los avances más notables de la LOCE y de los RR.DD. de desarrollo. Por otra parte tampoco se mezcla esta cuestión con la Educación cívica y la enseñanza de la Constitución sobre la que no se dice nada significativo. 


\section{Una solución inestable}

Desde el punto de vista externo, la LOCE puede resolver el problema sólo si se consigue un consenso duradero entre los dos principales partidos y entre las fuerzas sociales y culturales que se sitúan en sus áreas. Este consenso debe resolverse en tres momentos: debate público, pacto cívico y pacto político parlamentario a través de una LEY ORGÁNICA DE LA ENSEÑANZA DE LA RELIGIÓN, que no esté sometida a la variación de partidos gobernantes previsible en un sistema parlamentario.

Cualquier solución debe tener en cuenta que éste es un contencioso que dura ya muchos años, un problema no cerrado, al menos, desde la Segunda República. En aquellos años (desde 1931, agravada la situación en 1933) comienza una dinámica de exclusiones, que hace de la enseñanza escolar de la religión la única bandera de las izadas en los años 30 que todavía sigue sin ser arriada y sirve para diferenciar retóricamente a la derecha y a la izquierda. La Segunda Dictadura contribuyó a agravar el problema por la hipoteca política bajo la que retuvo a la religión católica durante casi cuarenta años. En los años 70 hubo intentos de una posición dialogada que fueron frenados, de la misma manera que los arreglos provisionales y pactados de la UCD en los primeros 80. Descuella en esos años un documento clave, las Orientaciones sobre Enseñanza Religiosa Escolar del Episcopado (junio de 1979), que siguen siendo vigentes y valiosas, aunque recientemente estén siendo erosionadas por la propia dinámica intraeclesial neoconfesional y por la agresión de la izquierda cultural y mediática. Los años de gobierno del PSOE han sido muy difíciles para la ERE, y sólo hacia 1995, bajo el ministro Suárez Pertierra, se comenzó a ver la salida del túnel, con una opción alternativa a la ERE Ilamada también SCR, que constituye el antecedente directo de la actual solución. Pero no es aceptable decir que la ERE empezó a tener problemas a causa del Gobierno del PSOE (en 1982) ni por la LOGSE (en 1990). El que lo afirme así se reduce a la apariencia de las fechas. La ERE sufre en España al menos desde los años 30; la larga noche de la Segunda Dictadura no le dio la estabilidad que retóricamente proclamaba el nacionalcatolicismo, antes al contrario, éste sirvió para el duradero descrédito de la enseñanza religiosa. Por otra parte muchas veces la propia jerarquía episcopal, que ha monopolizado excesivamente la responsabilidad sobre la ERE, ha tenido una visión muy coyuntural y eclesiocéntrica de ésta y ha bloqueado el desarrollo de sus dimensiones culturales, escolares y ciudadanas.

¿Qué ocurrirá con esta regulación tras una futura, siempre posible en la 
lógica de un régimen parlamentario de alternancia, victoria electoral del PSOE? Permítaseme, al menos, pensar que, así como al octavo año de su primera victoria electoral (1982) el PSOE abordó su verdadera reforma educativa con la LOGSE, sin consenso parlamentario, y el PP ha realizado su reforma educativa con la LOCE, sin consenso, al séptimo año de su primera victoria electoral (1996), un hipotético pero verosímil cambio de partido gobernante, plantea algunos serios interrogantes. Seis años, el tiempo transcurrido entre 1990 y 1996, fueron pocos para lograr la estabilidad educativa necesaria para desarrollar y aplicar una Ley que cambiaba sustancialmente el sistema educativo. En la hipótesis de un cambio de mayoría política en 2004 o en 2008 volvería a reproducirse la situación de permanente e inestable transición del sistema educativo, y dentro de él de forma muy acusada de la ERE, que la viene lastrando desde el final de la Segunda Dictadura. En dicha hipótesis de cambio de mayoría parlamentaria, volvería a repetirse la situación anterior: al año o a los cinco años de la LOCE, un partido socialista que retornase al gobierno del Estado volvería a estar en condiciones de hacer su contrarreforma educativa. No es difícil aventurar que el PSOE intentaría, más pronto que tarde, una inversión legislativa de la actual legislación del PP. Por eso interesa al mundo educativo que la actual reforma de la enseñanza escolar de la religión cumpla dos condiciones: estar bien fundamentada y ser resultado de un pacto social y político estable, el que, en otros escritos, he Ilamado 'Pacto cívico por una Enseñanza escolar de la Religión', que, previo un pacto parlamentario, dé lugar a una LEY ORGÁNICA DE LA ENSEÑANZA DE LA RELIGIÓN.

\section{Conclusión: una solución aceptable, pero provisional}

La LOCE y los RR.DD. de 27-6-2003 que desarrollan las enseñanzas comunes, han dado un giro a la regulación de la ERE, pero un giro en continuidad con la propuesta más inteligente del último de los Gobiernos de Felipe González ${ }^{11}$. Lo que el ministro Suárez Pertierra propuso para tres años de secundaria (14-17), la ministra Del Castillo lo ha propuesto para los

11 La resolución de 16 de agosto de 1995 fue resultado del trabajo de una Comisión en la que se encontraban personas de tanta calidad y tan significativas de la pluralidad como Victoria Camps, Olegario González de Cardedal, Miguel Herrero de Miñón, Juan A. Ortega DíazAmbrona y Gregorio Peces-Barba Martínez, entre otros. Los olvidos involuntarios se deben a que cito de memoria, pero estos cinco nombres son bien representativos del espíritu de aquella propuesta. El Instituto Fe y Secularidad de Madrid organizó unos años después un Simposio en el mismo espíritu. 
catorce años de primaria y secundaria en su conjunto; lo que fue una resolución ministerial, al amparo de una disposición adicional segunda de la LOGSE, distinta a la disposición adicional segunda de la LOCE, es ahora, al amparo de esta última, una más de las enseñanzas comunes, inserta en el conjunto de los Reales Decretos que regulan ésta. El giro es muy notable, pero la continuidad de la lógica de ambas posiciones también ${ }^{12}$. Mi punto de vista personal, que espero haber argumentado en las líneas anteriores, es que nos encontramos ante una buena solución que responde bien a las necesidades educativas de la sociedad española y de la sociedad europea ${ }^{13}$. Es una solución progresista y razonable, inscrita en el bloque de la constitucionalidad. Es una solución, sin embargo, problemática e inestable. Por ello es incompleta. Hasta que no se defina, clara y definitivamente, si la enseñanza de la religión en la escuela responde al que he llamado principio de integralidad 0 al de cooperación positiva desdela pluralidad, no podremos decir que la ERE, dentro de SCR en la actual regulación, ha encontrado su asiento definitivo en el sistema educativo dentro de la lógica constitucional. Pero esta definición del principio que fundamenta la ERE en el sistema educativo reclama un consenso social básico y un acuerdo parlamentario fundamental. Sin la deliberación de la sociedad civil y el acuerdo entre derecha eizquierda, la bandera retórica de la ERE seguirá izada. Sin deliberación y consenso democráticos, no es posible resolver este problema. El Gobierno actual ha propuesto una buena solución, pero ésta sólo será realmente estable cuando sea una solución aceptable para la inmensa mayoría parlamentaria, al menos para las dos grandes fuerzas del arco parlamentario. El Gobierno y el partido que lo sostiene deben abrir un debate de interpretación constitucional de esta Ley. La izquierda debería reconocer que ésta es una buena solución y, en lugar de las escaramuzas mediáticas estériles, aunque renten a corto plazo, debería contribuir al desarrollo y a la interpretación constitucional de

12 Acaba de notarlo persona tan bien informada y tan ecuánime como Francesc Rıv (2003), «Sociedad y religión», La Vanguardia, Barcelona, 6-7-2003, p.35. Me permito anotar la curiosidad siguiente: en el buscador dela página web del Ministerio de Educación (www.mecd) si se piden, las referencias de Sociedad, Cultura y Religión remite a la Resolución ministerial de 16-8-1995, y todavía no a los RR.DD. de 27-6-2003.

13 En Francia, por ejemplo, los sucesivos ministros de Educación, socialista y conservador, J ack Lang y Luc Ferry, han impulsado el debate en favor de una enseñanza religiosa desde la laicidad republicana, y el intelectual de izquierdas Régis Debray ha contribuido al mismo. En uno de los símbolos de la laicidad universitaria que es la École Pratique des Hautes Études (ÉPHÉ) acaba de crearse un Instituto europeo de las ciencias religiosas (IESR); Cfr. TINCQ, H. (2003), Le Monde 3-7-2003, pp. 1 y 15. 
la LOCE y de los decretos que la desarrollan. El año electoral que comienza en septiembre (Madrid y Cataluña en otoño de 2003, Andalucía y Políticas en marzo de 2004, y quién sabe si el País Vasco) no es el tiempo mejor para debatir en serio estas cuestiones. Pero hemos de ir preparando los argumentos y las sensibilidades para la primavera de 2004. Algún día llegaremos a una regulación de las enseñanzas escolares de la Religión de acuerdo con el espíritu y con la letra de la Constitución. A esto parece apuntar el camino iniciado y a esto quiere contribuir esta modesta nota: una enseñanza de la religión dentro de la Constitución. 